\section{EL CINE EXPERIMENTAL DE MUJERES: ANTECEDENTES Y DESARROLLO DEL CINE TEÓRICO FEMINISTA DE LOS 70 EN EL REINO UNIDO}

\author{
Carmen Pérez Ríu \\ Universidad de Oviedo \\ perezcarmen@uniovi.es
}

\section{WOMEN'S EXPERIMENTAL CINEMA; ANTECEDENTS AND DEVELOPMENT OF FEMINIST FILM IN THE 1970 S IN THE UK}

RESUMEN: Este artículo analiza la obra experimental de mujeres centrándose principalmente en la que se produjo durante los años 70 en el Reino Unido y su vinculación con la teoría cinematográfica feminista. La primera parte hace un recorrido por la participación de las mujeres en las diferentes corrientes y movimientos del cine experimental desde la década de los 20 hasta los 70. Esta sección tiene como finalidad situar a las directoras experimentales británicas de los 70 dentro de un panorama global mucho más complejo incluyendo las influencias que recibian desde Europa y EE.UU., donde se encontraba el centro neurálgico de las corrientes cinematográficas de vanguardia. Una segunda parte estudia con más detenimiento el fenómeno del cine experimental feminista en Inglaterra durante la década de los 70, con atención especial a las dos cineastas fundamentales de este fenómeno: Laura Mulvey y Sally Potter. A modo de conclusión se incluyen unas características generales del cine experimental de mujeres.

PALABRAS CLAVE: Cine experimental, feminismo y cine, cine teórico, Laura Mulvey, Sally Potter, vanguardia cinematográfica.

LOS ORÍGENES: DIRECTORAS EN LA VANGUARDIA EXPERIMENTAL (1920-1970)

El cine experimental comienza con las incursiones en el medio cinematográfico de un número de artistas de vanguardias (Dada y Surrealistas), como extensión de las artes plásticas a comienzos de los años 20. Los artistas experimentales de este período, hombres casi exclusivamente, exploraban todo tipo de soportes a los que trasladaban su interés por cultivar el lenguaje formal en lugar de elementos figurativos o narrativos. Este énfasis anti-ilusionista, proveniente de las artes plásticas, simultáneamente conseguía un deseado distanciamiento del cine comercial para comenzar a utilizar el cine puramente como medio de expresión estética. Como botón de muestra puede citarse La retour à la raison (Man Ray, 1923) o la abstracta Ane-
ABSTRACT: This article analyses experimental films made by women between 1920 and 1979, focusing particularly on films produced during the 1970s in the UK and their links to feminist film theory. The first part deals with the participation of women in the experimental film movements from the 1920s to the 1970s. The aim of this section is to provide a context for British experimental women directors during the 1970s within the more complex background of experimental film movements, with influences from the nerve centre of the AvantGarde in Europe and the USA. The second part studies the development of experimental feminist film in the UK during the 1970s, with special attention to two essential filmmakers, Laura Mulvey and Sally Potter. The article concludes with a discussion of some general characteristics of experimental films by women.

KEY WORDS: Experimental film, feminism and film, theoretical film, Laura Mulvey, Sally Potter, Avant-Garde cinema.

mic cinéma (M. Duchamp, 1926). ${ }^{1}$ En EE.UU., e inspirado por esta corriente europea, se desarrolló un movimiento autodefinido como amateur que recibió un fuerte impulso con la aparición de la cámara de $16 \mathrm{~mm}$ en 1924 (Horak en Dixon \& Foster, 2002, 19-51). ${ }^{2}$ Este grupo incluía a algunas mujeres como Mary Ellen Bute, que realizó cortos de animación abstractos utilizando la sincronía con piezas musicales clásicas (por ejemplo Rhythm in Light, 1935 o Syncromy n.2, 1936); y también Stella Simon, cuyo filme Hands (1928) elabora un melodrama romántico utilizando la danza de las manos como personajes. Más o menos simultáneamente, la francesa Germaine Dulac también estaba dirigiendo películas innovadoras y personales con las que desarrolló las capacidades expresivas del lenguaje cinematográfico y los medios técnicos disponibles. Dulac realizó 26 películas entre 1916 y 1929, de las cuales solo 
dos se conservan completas, La Souriante madame Beudet (1922) y La coquille et le clergyman (1927), pero ambas han sido muy influyentes en círculos de vanguardia. La primera, sin llegar a ser un filme experimental, utilizaba técnicas impresionistas para expresar la subjetividad del personaje femenino central. "Dulac, como los demás impresionistas (Delluc, Epstein, Gance), influidos por el arte postsimbolista, y por la narrativa de Proust y de Gide, cultivaban un conjunto de recursos para representar los estados interiores de los personajes" ("Miradas"). Este filme es un importante referente para el cine feminista por la forma en que representa la opresión de la protagonista dentro de su matrimonio burgués y sus fantasías escapistas.

La coquille et le clergyman (1927) es un texto plenamente experimental; se trata de un filme con guión del dramaturgo Antonin Artaud y que algunos autores consideran el primer filme surrealista (Heck-Rabi, 1984, 44). Los personajes son un clérigo, un oficial del ejército y una mujer y su fantasma. El filme incluye persecuciones por salones de baile, habitaciones vacías y largos pasillos, escenas alucinatorias de rostros deformados, una lengua que se alarga hasta el infinito, la concha del título es utilizada en la elaboración de brebajes, así como otras escenas de corte surrealista. Según han contado diversos comentaristas, Dulac no permitió a Artaud participar en el rodaje ni en el montaje de La coquille e incluyó entre los créditos del filme un rótulo afirmando que se trataba de "un sueño de Antonin Artaud". Esto provocó el enfado de Artaud, que protagonizó una sonora protesta durante el estreno del filme. Según la analista Wendy Dozoretz, entre otras cosas, acusaba a Dulac de haber "feminizado" su texto (citado en Heck-Rabi, 1984, 47). Heck-Rabi sugiere que esa "feminización" puede haber consistido en una suavización de algunos de los elementos más radicales del guión.

Tras una fructífera producción cinematográfica, Dulac vería progresivamente recortadas sus capacidades de acceder a los medios de producción, tanto más cuanto, después de la irrupción del sonido, los costes se encarecieron. Esto, unido a sus propias reticencias a participar en el cine sonoro, puso fin a su carrera como cineasta; puesto que, en palabras de Susan Hayward, "[s] he believed that too much emphasis would be placed on the talking voice and not enough on the orchestration of meaning through movement and image -and eventually, that would marginalize her praxis" (citado en Mounsef, 2003, 41).
Durante la década de los 40, Maya Deren lideró un resurgimiento del cine experimental de naturaleza psicoanalítica, que serviría como referente y modelo para un gran número de mujeres directoras que posteriormente recurrieron a los lenguajes experimentales. Deren habia nacido en Kiev en 1917 pero su familia emigró a EE.UU. en 1922 y, tras estudiar periodismo y danza, y gracias al apoyo inicial de su marido A. Hammid, accedió a la dirección cinematográfica y desarrolló su trabajo principalmente desde Nueva York (Heck-Rabi, 1984, 196). La obra más influyente de Deren, Meshes of the Afternoon (codirigida con Hammid en 1943) se vincula también con el surrealismo, pero adoptando una estética transgresora en la que la visión como mujer es fundamental. ${ }^{3}$ Maureen Turim interpreta la estructura fragmentada con elementos recurrentes de este filme $y_{\text {, }}$ en particular, sus imágenes violentas, como una forma de representar lo que ella denomina "fantasy riddled with parapraxis" (Turim en Petrolle \& Wright eds., 2005, 75). Siendo las parapraxis huellas de acciones fallidas en el inconsciente, las constantes repeticiones, reelaboraciones e imágenes simbólicas constituyen, para esta autora, reflejos de acciones que fallan a causa de un deseo o conflicto no expresado (Turim en Petrolle \& Wright eds., 2005, 75). Sin embargo, como apunta también Turim, Deren se resistió siempre a la interpretación psicoanalítica de sus filmes:

Deren's violence and embrace of the unexpected in fantasy are elements that link her work to surrealism, and like that movement, she famously argues against psychoanalytic decipherment. What seems to bother her is a one-to-one matching of interpretation with images that can account neither for transformative energies nor structure. Instead, as in surrealism, Deren creatively mobilizes elements of the dream to unleash the power of the unconscious, illustrating its violence through filmic cutting. (Turim en Petrolle \& Wright eds., 2005, 76)

Tanto Dulac como Deren contribuyeron a la teorización de la vanguardia cinematográfica con escritos sobre estética y significado del filme, abogando por su desarrollo como un lenguaje artístico puro. Dulac creó su propia revista, Schémas, cuyo único volumen, escrito y editado por ella misma, salió en 1927. ${ }^{4}$ Deren daba conferencias y escribia también en numerosas revistas, además de ser autora de una publicación más extensa titulada An Anagram of Ideas on Art, Form and the Film (1946), donde, en palabras de Heck-Rabi "[she] projects two major premises: the rejec- 
tion of symbolism in film and an analysis of independent and industrial film-making, with a strong option for the former" (Heck-Rabi, 1984, 212).

Otro ejemplo de mujeres trabajando en la vanguardia cinematográfica durante la década de los 40 es el de Sara K. Arledge, que se había formado como pintora y bailarina y cuyo filme Introspection (1941-46) refleja su preocupación por la representación del cuerpo humano a través de la danza y la manipulación estética (imágenes superpuestas, filtros de colores, personajes envueltos en tela o con los rostros pintados) (Horak en Dixon \& Foster, 2002, 36). Y, ya en los 50, la belga Agnes Varda, considerada la única representante femenina de la Nouvelle vague, realizó cortos experimentales en sus comienzos como La Pointe Courte (1955) y L'Opera Mouffe (1958) y desarrolló un estilo personal para un público más amplio en filmes como Cléo de 5 á 7 (1961), incluyendo algunos textos vinculados directamente al activismo feminista de la década de los 70, como Réponse de femmes (1975) y L'une chante, I'autre pas (1977).

La obra y pensamiento de estas artistas inspiraron a otras muchas mujeres a utilizar el medio como forma de expresión en etapas posteriores, especialmente durante el resurgimiento de la vanguardia norteamericana en los 60. Esta etapa de los años 60 fue un momento de florecimiento y expansión, vinculado al estructuralismo/materialismo de Michael Snow, Andy Warhol y Stan Brakhage y apoyado por la recién creada Filmmakers Cooperative en EE.UU. Esta agrupación de los cineastas experimentales impulsada por Jonas Mekas y Shirley Clarke tenía como objetivo facilitar los medios de producción y sobre todo de exhibición de los filmes. Su equivalente en Reino Unido fue la London Filmmakers' Co-op. Shirley Clarke, seguidora y amiga de Maya Deren, también había accedido al cine a través de su formación en la danza y su interés en reflejarla en forma cinematográfica (Dance in the Sun, 1953). Asimismo, en los 60 desarrollaron su obra otras directoras norteamericanas como Marie Menken, representante del cine-poesía, la polifacética Storm de Hirsch, o Barbara Rubin, que rodó su primer film (Christmas on Earth, 1963) cuando contaba con tan solo 18 años (Dixon y Foster, 2002, 8) y Carolee Schneemann, también vinculada con el estructuralismo. La obra de estas artistas coincide temporalmente con la nueva ola de vanguardias. Fue en este ambiente en el que comenzó a trabajar la sueca Gunvor Nelson, que realizó diez cortos experimentales entre 1965 y 1979 (en su mayoria en colaboración con Dorothy Wiley) y otros muchos después en solitario ya de vuelta en su país natal, incluyendo obra reciente en vídeo. A Nelson se la tildó de cineasta "femenina" o "feminista" en sus comienzos, cuando accedió a la escena del cine experimental de la costa oeste durante los 60 , aunque ella ha rechazado en alguna ocasión el término (Holmlund en Blaetz ed. 2007, 68). Al igual que otras artistas del momento, Nelson emplea técnicas abstractas, explora la animación, se muestra a sí misma y a miembros de su familia, utiliza elementos plásticos frecuentes en el cine experimental como imágenes superpuestas y la pintura o manipulación de objetos.

El movimiento Fluxus, que se gestó a caballo entre Alemania y Nueva York en los años 60, también tuvo su manifestación en cine, así como una de sus más famosas representantes en Yoko Ono. George Maciunas es conocido como el fundador de esta corriente, a la que dio nombre al escoger el título "Fluxus" para la revista que serviría como escaparate y elemento aglutinador. Herederos del Dada, abogan por un "arte total", sin pretensiones y con una extraordinaria libertad creativa. Estas son sin duda dos de las características de Ono como cineasta experimental. Ono participó activamente en el movimiento, organizando "events" en su loft que incluían todo tipo de manifestaciones artísticas.

There is a "what if?" "why not?" "what the hell?" quality to a lot of Fluxus art, which can be attributed to the artists questioning the limits of art. What is art? What isn't? Ono once said that everyone could be artists and everything could be art. There were Fluxus publications, Fluxus concerts, Fluxus films, Fluxus readymades, Fluxus multiples, Fluxus prints and graphics. (Chin en Dixon y Foster, 2002, 218)

La actividad cinematográfica de Ono se desarrolló principalmente durante la década de los 60 e incluye títulos como $N^{\circ} 4$, también conocido como Bottoms (1966), que tiene dos versiones, en cinco o en ochenta minutos, 0 No 5 (Smile) (1968), que consiste en un plano estático del rostro de John Lennon de 51 minutos, en el que finalmente sonrie. En películas como Rape (1969), Erection (1971) o Up your Legs Forever (1970), Ono jugaba con un título de connotación sexual para expresar otros sentidos, lo que resume muy bien su actitud irónica y humorística ante el arte. Erection se refiere en realidad a la construcción de un 
edificio y en Rape la violación era psicológica y consistía en la elección de una mujer al azar en la calle a la que la cámara seguía durante todo un dia, ejerciendo una violación de su intimidad y libertad individual. Evidentemente, con este texto Ono hacía también una reivindicación feminista sobre la experiencia de las mujeres; al igual que en su performance filmada Cut Piece, en la que invita a los espectadores a subir al escenario, blandir unas tijeras y cortar fragmentos de su vestido hasta quedar prácticamente desnuda en escena.

\section{El panorama del Cine experimental duRANTE loS 70}

Los artistas/cineastas europeos que se apuntaron a la corriente experimental materialista/estructuralista incluyen a Peter Gidal, Anthony McCall y William Raban, ya en los 70, así como representantes de la vanguardia alemana como Lutz Mommartz y el matrimonio Wilheim y Birgit Hein, y de la vanguardia austriaca, que incluye entre otros a Kurt Kren o Ernst Schmidt. La pareja Straub-Huillet ejercieron como directores experimentales en Alemania, con Danièle Huillet a veces no citada como directora. Su filme Chronik der Anna Magdalena Bach (1968), un comentario sobre la vida y obra de Johan Sebastian Bach desde la perspectiva de su segunda esposa, subraya irónicamente este hecho.

Además de Birgit Hein, el estructuralismo fue practicado, si bien brevemente, por mujeres europeas como la belga Chantal Akerman (News from Home, 1976) y la francesa Claudine Eizykman (VW vitesses women, 1974) y por algunas mujeres cineastas en Norteamérica. Este fue el caso de la canadiense Joyce Wieland, que estaba casada con Michael Snow, y de Marie Menken, que pertenecia al círculo de Andy Warhol's Factory (Ravinovitz en Dixon y Foster, 2002, 71). La californiana Chick Strand combinó las técnicas experimentales con la etnografía cinematográfica. A pesar de esto, la crítica y los medios de producción no siempre valoraron suficientemente la obra de las mujeres y a veces la excluyeron de los estudios teóricos y críticos. ${ }^{5}$ La escocesa Annabel Nicolson fue parte muy activa de la London Filmmaker's Co-op durante los 70, donde ejercía como programadora cinematográfica y fue co-fundadora de la distribuidora de películas de mujeres Circles (1980). Su propia obra cinematográfica es principalmente abstracta, explorando las cualidades plásticas de la imagen filmada, a menudo de paisajes, así como el color y el tiempo o la exposición. También manipula la película propiamente dicha, pintando o arañando los fotogramas. Con Reel Time (1973), que es una performance cinematográfica, causó gran impacto al utilizar una máquina de coser cuya sombra se recorta sobre dos pantallas, con la que perfora y manipula las bobinas de película que luego son proyectadas. Este texto también vincula a Nicolson con el movimiento feminista: "The Singer sewing machine [...] is both a familiar household object and potent symbol of women's hidden labour in the home and in sweatshops; by contrast the film projector [...] symbolises a vast maledominated entertainment industry" (Sparrow).

Otra película influyente en el ámbito de las cineastas experimentales europeas fue Deux fois (1971), de la francesa Jackie Raynal. Raynal había ejercido como montadora para algunos de los cineastas de la Nouvelle vague y se unió al grupo experimental Les Films Zanzibar, que surge a raiz del Mayo del 68. La película está protagonizada por su propia directora, que comienza el filme explicando a cámara el contenido del mismo y terminando con la enigmática frase: "Cette soirée sera la fin de la signification. Mesdames, monsieurs, bon soir". En la extraña historia del encuentro entre una mujer y un hombre utiliza repeticiones, el sueño, la violencia y el expresionismo. "If Deux Fois shows a dream-world it is only a broken, shuttering, intermittent vision. Some images of the film seem heightened, romantic, expressionist, oneiric (like the phantasmal image of Raynal struggling against the wind). But they rise up in the middle of more mundane documentary-like material" (Martin, 1999, 4).

Otra cineasta fundamental de esta época fue Chantal Akerman, especialmente con Je, Tu, II, Elle (1974) y Jeanne Dielman, quai du Commerce 1080, Bruxelles (1975). Jerry White establece tres épocas diferenciadas en la filmografía de Akerman: "Avant-garde/structuralist; counter cinema/ deconstructionist; and conventional art film (White en Petrolle y Wright, 2005, 47). Los dos filmes mencionados pertenecen claramente a la estética de counter cinema, en la que se percibe una intención política feminista. En Jeanne Dielman, una película de tres horas y media aproximadamente de duración, la indolente repetición de labores domésticas con la cámara estática ${ }^{6}$ comunica la opresión de la protagonista y su distanciamiento emocional de su experiencia de la realidad. Las relaciones sexuales que 
mantiene con desconocidos como única fuente de ingresos, junto con sus conversaciones sobre sexo con su hijo adolescente, remiten a la dimensión psicoanalítica de la escena primaria. Su tenue equilibrio emocional se desvanece cuando siente algo (un orgasmo quizá) durante el coito con uno de sus clientes. El desenlace violento del texto supone una ruptura radical del distanciamiento del personaje de su propia psique, que le permitía mantener una existencia soportable. Sobre la vinculación feminista de este texto, Judith Mayne afirma:

From the resurrection of the pre-oedipal and the attendant child-mother bond in feminist psychoanalytic writing, to the insistence on the body in discourse in l'ecriture feminine, to the conceptualization of a female aesthetic defined in so-called pre-aesthetic terms, contemporary feminism has been obsessed with the excavation of a space, an area, somehow prior to and therefore potentially resistant to the realm of the patriarchal symbolic. (Mayne en Dixon y Foster, 2002, 93)

\section{LA VANGUARDIA TEÓRICA FEMINISTA EN LA DÉCADA de los 70 en Gran Bretaña}

Como es sabido, el inicio de la década de los 70 vio la creación de un sólido movimiento de crítica y teoría cinematográfica feminista. Según subrayan, por ejemplo, Robin Blaetz (2007) y Ruby Rich (1998) este movimiento se apoyaba en la obra teórica y crítica reciente -así, el influyente Sexual Politics de Kate Millett había visto la luz en 1970 y esta autora norteamericana se interesó por el cine (actuando como productora del documental Three Lives, 1971) - y en una serie de acontecimientos fundamentales para cohesionar el movimiento teórico y crítico feminista del cine. Toda la década estuvo plagada de hechos significativos, de los que destacaremos a modo de ejemplo los que sucedieron en un solo año, 1972: comenzando por la creación de la revista Women and Film (1972-1975) y el London Women's Film Group (1972), que vinculó a mujeres que participaron colectiva o individualmente como directoras en películas producidas por el grupo (formado por cineastas de escasa trayectoria posterior, como Francine Winham, Susan Saphiro, Linda Dove, Mary Capps, Mary Kelly, Margaret Dickinson, Esther Ronay, o Brigid Segrave).
También fue muy importante en ese mismo año la celebración del primer festival de cine de mujeres en NY y de la sección de cine de mujeres, "The Women's Event", en el Festival de Cine de Edimburgo así como monográficos dedicados al cine de mujeres en dos reputadas revistas especializadas, Take One y Film Library Quarterly. Según afirma Blaetz, las películas mostradas en los festivales que se celebraron en estos momentos incluian filmes de Dorothy Arzner, Mai Zetterling, Agnes Varda; y en algún caso, también experimentales como los de Deren, Menken, Gunvor Nelson y Dorothy Wiley o Chick Strand (Blaetz, 2007, 3-4).

En este ambiente se gestó la obra cinematográfica y teórica de las británicas Laura Mulvey y Sally Potter, dentro de la corriente que se suele denominar como cine teórico de vanguardia o cine feminista. La clasificación que hace Ann Kaplan de este subgénero distingue tres tendencias: las películas que pretenden dar voz a la subjetividad femenina, las que tienen como objetivo deconstruir los textos masculinos clásicos y, por último, el que probablemente es más numeroso pero también menos estudiado, un tipo de documental que analiza desde una perspectiva teórica y realista el tratamiento de la historia de las mujeres; Kaplan cita como ejemplo Song of the Shirt (1979), de Sue Cayton y Jonathan Curling (Kaplan, 1998 [1983], 250-252). Dedicaremos ahora atención a los dos primeros tipos, ya que son los que produjeron películas claramente experimentales. Y lo vamos a hacer fijándonos en tres filmes británicos: Thriller, de Sally Potter, Penthesilea, Queen of the Amazons y Riddles of the Sphinx, ambas de Laura Mulvey y Peter Wollen. La teoría cinematográfica feminista llevaba ya algún tiempo haciendo una crítica contra la representación fetichista de las mujeres en el cine clásico, que promovía el voyeurismo y la objetivización del cuerpo femenino para el placer visual. Tras hacer un análisis teórico de los modos en que los textos conseguían esos efectos (Molly Haskell, Claire Johnston y artículos de otros autores aparecidos en publicaciones como Women and Film y Camera Obscura) era el momento de tratar de presentar alternativas. Las técnicas experimentales permiten una huída de la narración clásica, con la que se evitan conscientemente los planos que manipulan la recepción, como por ejemplo la técnica del plano/contraplano, que determina la formación de expectativas en un sentido lineal. 


\section{El filme teórico feminista en Gran Bretaña: Sally Potter y Laura Mulvey}

El término "cine teórico feminista" se refiere por tanto a un movimiento artístico, cultural y político cuyo origen es minoritario y de vanguardia. Sally Potter es una de las principales representantes. Thriller la lanzó en el medio cinematográfico al adquirir popularidad y ser premiada en los festivales de cine independiente (Berlín, Florencia, Edimburgo). Se trata de un cortometraje que re-elabora la historia narrada en la ópera La Bohéme, con lo que constituye una lectura "a contra pelo" de la tradición cultural europea.

En su versión, Potter se instala en un género cinematográfico bien conocido y con un ritual marcado, el del thriller, para desestabilizarlo. La reescritura crítica del melodrama operistico de La Bohéme, apoyada en la ginocrítica y en la teoría psicoanalítica feminista, le da opción a dotar al personaje de Mimí de una voz y por lo tanto permite reflejar su punto de vista, no como víctima, sino como agente en su propia historia a través de la investigación de su muerte. Formalmente el filme remite, por oposición, a la estética de los dos géneros a los que se enfrenta. De este modo, se opone también a su contenido ideológico. A través de una escenografía opresiva, una estructura circular y técnicas visuales experimentales, deconstruye las formas de representación que en el melodrama clásico hacian de los personajes femeninos víctimas propiciatorias para construir la tragedia.

El filme comienza, con un fundido en negro, en el punto en el que la ópera termina: Mimí, la costurera enfermiza acaba de morir de debilidad en los brazos del protagonista masculino, Rodolfo, que aunque la ama, la ha abandonado porque no puede mantenerla económicamente, y se oye la bella y trágica aria final. Esta música es interrumpida por los agudos acordes de violín del apuñalamiento de Psicosis. Este comienzo supone un cambio de género para la historia de Mimí indicado con una referencia audible y reconocible para el público. No se trata de un melodrama trágico, sino de un thriller; es decir, que la de Mimí, para Potter, no es una muerte trágica sino un asesinato que da pie a una investigación para hallar al asesino. En el filme de Potter Mimí es negra (interpretada por la actriz Collette Laffont), lo que añade una connotación racial, ${ }_{1}^{8}$ y es ella misma quien realiza la investigación haciéndose preguntas: ¿Estoy muerta?, ¿fui asesinada?, y si es así, ¿quién me mató y por qué? Sucesivamente en el filme se van plateando todas las preguntas relevantes: ¿por qué han de morir las mujeres en los relatos?, ¿por qué son las víctimas en incontables thrillers?, ¿qué hay en esto de emocionante?, ¿para quién lo es y por qué? Potter enfrenta a los espectadores con estos y otros interrogantes para llegar a la conclusión de que efectivamente fue un asesinato, y de que fue cometido por una tradición de pensamiento en el contexto de éste y otros relatos de dicha tradición. Historias en las que la heroína inocente, sumisa, pura, (es decir, el ideal femenino del patriarcado) debe ser sacrificada para que el héroe romántico pueda elevar su sufrimiento a la categoría de arte.

En La Bohéme Mimí representa el ideal femenino y la prostituta Mussetta el opuesto negativo. Marcia Landy señala entre las características del melodrama clásico la recurrencia de los temas y tratamientos sentimentales, la tendencia a establecer criterios morales polarizados, la incidencia de la violencia y el sufrimiento y la transposición de los problemas públicos y sociales al conflicto individual que se desarrolla en la esfera doméstica (Landy, 1991, 189-193). En lo referente a los personajes femeninos esto suele concretarse en la oposición entre un ideal femenino, dócil, inocente y sacrificado, y su opuesto, la mujer rebelde, moralmente censurable y sexualmente liberada. Landy explica a su vez que los personajes femeninos del melodrama "are not fully rounded characters, and they are not psychologically complex. They are identifiable by their polarized nature, their representation of specific moral qualities, their likeness to the split figures in dreams, and their relation to fantasies" (Landy, 1991, 197). El desenlace de este tipo de narraciones suele llevar al personaje femenino a la muerte, que supone una derrota de la fantasía negativa o una sublimación del ideal femenino. En el caso concreto de esta ópera (basada en la novela de Henri Murger, La Vie Bohéme), Puccini parece haber estado muy interesado en que la muerte de Mimí resaltara la fuerza trágica de su música y del propio personaje de Rodolfo. Ann Kaplan cita en su libro Las Mujeres y el Cine la siguiente frase de Puccini en una carta: "Cuando esta joven, por la que tanto he trabajado, muere, me gustaria que dejara el mundo menos por sí misma y un poco más por el hombre que la amaba" (Kaplan, 1998 [1983], 278).

Al comienzo de la película de Potter, Mimí se da cuenta de que la narración clásica anula por completo su punto de 
vista y evita contar nada de su experiencia vital. Reflexiona sobre las condiciones de su trabajo, el frío que la mantiene siempre enferma. Para Potter, Mimí es una representante de la clase trabajadora, su pobreza es muy diferente de la de los artistas bohemios, para quienes ser pobres es una forma de ser rebeldes contra el materialismo burgués. Ella carece, al contrario que los personajes masculinos, del honor de la creación artística. Irónicamente, Mimí borda flores para venderlas por poco dinero, pero en una clara jerarquía de las artes, esto no es comparable con la nobleza de los artistas bohemios. Después Mimí se plantea su relación con Musetta. La voz de Mimí en Thriller lamenta que nunca se hicieran amigas: "Nos separaron como opuestos, como personajes característicos para cumplir cada una nuestra función", y acaba por concluir que, en efecto, se trató de un asesinato, puesto que su muerte consiguió que los artistas se convirtieran en héroes en el despliegue de su dolor. Al final de Thriller, las dos mujeres se abrazan. La solución de Potter se dirige hacia la amistad y el apoyo entre las mujeres, un tema a su vez poco frecuente en las narraciones clásicas.

Las técnicas vanguardistas y expresionistas permiten una libertad estética que construye un nuevo lenguaje a través de la deconstrucción de los dos géneros, el melodrama y el thriller. La estructura está fragmentada, con el uso frecuente de elipsis y la yuxtaposición de secuencias que requieren la interpretación del público para reconstruir las relaciones entre ellas. También el sonido está descoordinado con la imagen, como por ejemplo las risotadas, los alaridos o el latido de un corazón. La estructura de este filme se ha de describir como cíclica y está organizada en niveles: la historia de Mimí es narrada tres veces, abundando en repeticiones y reiteraciones visuales que retoman los mismos elementos con cambios significativos. En el primer nivel Mimí cae en la cuenta de su situación, narrando el relato de La Bohéme en tercera persona. Al finalizar esta parte se enfrenta al espejo, lo que constituye el nivel psicoanalítico. La puesta en escena contribuye a este mensaje; el ático vacío que contiene solamente un espejo representa a la psique, pues es el lugar del reconocimiento y de la toma de consciencia individual. Frente al espejo llega a reconocerse y a darse cuenta de que en la ópera le fue negada su identidad; de este modo puede empezar a estar representada ella misma. En una segunda parte vuelve a contar la historia pero ya lo hace en primera persona y progresa contrastando el relato con clásicos del pensamiento patriarcal: hojea libros de Marx, Freud, Mallarmé, solo para rechazarlos con una risotada. Finalmente, una vez descartada la teoría, Mimí vuelve a contar de nuevo el argumento y se enfrenta con su historia considerándola como una narración que ha surgido en un contexto histórico. Así se da cuenta de que ella tenía que morir para seguir siendo el ideal sublimado; si no, se habría convertido en madre o en una anciana, que no son el tipo de personajes románticos con los que sueñan los hombres. De este modo comprende el efecto que tiene la oposición entre ella y Mussetta y lamenta la separación entre ambas que evita la unión entre las mujeres: "si nos hubiéramos conocido quizás nos habríamos amado". En Thriller, Sally Potter construye un texto de lo que Claire Johnston calificó como "counter cinema" (1973) o que, como decía Kaplan, responde a la intención de deconstruir los textos patriarcales clásicos. Las dos películas de Laura Mulvey que comentaremos responden al objetivo de generar un nuevo lenguaje cinematográfico que, a su juicio, fuera más aceptable para las mujeres.

Como otras muchas directoras hasta los 70, Laura Mulvey accedió a la dirección cinematográfica en colaboración con su marido, Peter Wollen, que también era crítico y teórico del cine. Ambos escribieron y codirigieron seis películas, en las que recurrieron a las técnicas experimentales. Los dos primeros filmes, Penthesilea, Queen of the Amazons (1974) y The Riddles of the Sphinx (1977) son una puesta en práctica de técnicas cinematográficas para dar una respuesta a las preocupaciones teóricas de Mulvey (y también de Wollen) durante los 70. Laura Mulvey había participado activamente en el movimiento cinematográfico feminista a comienzos de esta década. Había formado parte del comité organizador de aquella primera sección femenina del Festival de Edimburgo en 1972 y también del que montó el Festival de Cine de Mujeres en Chicago en el 74. Su artículo, "Visual pleasure and narrative cinema", fundamental para toda la crítica cinematográfica feminista posterior, apareció por primera vez en Screen en $1975 .^{9}$ Estas dos películas de Mulvey suponen una puesta en práctica de dos nuevos planteamientos teóricos recogidos en el artículo de Screen: la búsqueda de un lenguaje cinematográfico que diera expresión a la subjetividad de las mujeres y la identificación de una posición nueva para la espectadora en el texto, que no la obligara a participar de las estructuras de placer del cine clásico. ${ }^{10}$ 
Penthesilea contiene cinco secciones rodadas en una sola toma sin cortes aparentes. Cada una de las secciones remite a un tipo de lenguaje de los que intervienen en el cine: el elemento profílmico, en este caso proveniente del teatro, de la mímica del cuerpo; el lenguaje verbal hablado y escrito; las imágenes, que remiten a las artes plásticas; el cine, en forma de metraje de un filme antiguo; y el vídeo, que puede representar las técnicas modernas y una dirección de futuro para el cine experimental, aunque, como Mulvey y Wollen manifiestan, no cierra la búsqueda de un lenguaje alternativo (Mulvey y Wollen en Johnston y Willemen, 1974, 3). Penthesilea comienza con la representación mímica de la versión del mito clásico del dramaturgo Heinrich von Kleist y continúa con una explicación leída por Wollen a cámara sobre los objetivos del filme. Este recurso, como afirma Wollen en el texto, tiene por objetivo cuestionar el mundo de ficción creado por el cine. En el marco de esta ruptura del ilusionismo cinematográfico el filme replantea el mito de la reina guerrera que se enfrentó a Aquiles. Su historia se sugiere a través de imágenes muy variadas y cronológicamente distantes de las amazonas. En la siguiente sección del filme el rostro de una mujer se superpone al metraje antiguo tomado del filme What 80 Million Women Want (1913) sobre el movimiento sufragista. En la banda sonora se escucha una lectura de las cartas de la activista sufragista norteamericana, Jessie Ashley, junto con voces de mujeres y sonido de maquinaria. La quinta parte muestra simultáneamente cuatro imágenes de vídeo que recogen fragmentos de las secciones anteriores, junto con una quinta en la que se puede ver a la actriz que ha interpretado el mimo de Pentesilea quitándose el maquillaje, mirando a cámara, etc. Entre las técnicas experimentales," por ejemplo, está el hecho de no utilizar montaje, el uso de metraje encontrado y de imágenes variopintas que forman un puzzle que desafía la interpretación lineal y la pasividad del espectador. El manejo de la cámara en la secuencia dedicada al lenguaje verbal evidencia también una vinculación técnica con la vanguardia: la cámara, a veces sostenida a mano, se aleja del objeto filmado en movimientos perfectamente coreografiados y muestra el texto escrito en unas tarjetas (que se supone que Wollen está leyendo, pero que no tienen el mismo contenido).

Por lo que respecta al significado de este filme, el recurso a la historia mitológica de las Amazonas tiene que ver con la necesidad de encontrar bases simbólicas para una forma de expresión propia de las mujeres. El énfasis central es la búsqueda de un nuevo lenguaje que no responda al orden simbólico del patriarcado, aunque en esta misma entrevista los directores dejan claro que no pretenden ofrecer respuestas, sino más bien plantear preguntas. Según afirma Mulvey, las diferentes partes son una forma de repetición transformada, en la que el lenguaje está disponible solo hasta cierto punto: reprimido en la primera parte, donde la mímica sustituye al texto verbal, cuestionado por la disyunción entre palabra escrita y oral en la segunda parte, negado en la tercera, en la que la banda de sonido presenta ruidos inconexos que aluden a la búsqueda fallida de un lenguaje; e inútil o banal en las dos últimas partes: "Although she takes off her make up to get access to verbal language at the same time, when she does speak, it is clearly a performance. It is not 'her' speech" (Mulvey y Wollen en Johnston y Willemen, 1974, 7).

Aunque también fue codirigido con Peter Wollen, Riddles of the Sphinx (1977) es un filme más personal de Laura Mulvey, puesto que el guión está por completo a su cargo y en la escena paralela a la de Penthesilea en la que los directores explican los objetivos del filme a su audiencia, es Mulvey y no Wollen quien lee a cámara. De nuevo el filme está fragmentado en siete partes, de las cuales las tres primeras forman una especie de prólogo teórico-visual al relato de ficción y las tres últimas contienen un resumen paralelo a modo de epílogo. En el prólogo diferentes imágenes de esfinges (incluyendo una famosa de la esfinge de Gizeh con el rostro de Greta Garbo) hacen el vínculo con la dimensión mítica y psicoanalítica del principal referente del filme. En su comentario, Laura Mulvey explica que la esfinge actuará como narradora de la historia porque su voz permanece externa a la sociedad patriarcal, igual que la esfinge estaba fuera de los muros de la ciudad de Tebas, y también porque su función es hacer preguntas, plantear enigmas. La sección central, en la que el filme narra la historia de Louise propiamente dicha, está filmada por medio de trece panorámicas circulares muy lentas. Las dos primeras muestran el ambiente doméstico, la unión entre la madre y su hija Ann, en la que brevemente irrumpe la mano y la voz del padre. Se sugiere que Louise quizá esté demasiado próxima a su hija. Ann Kaplan interpreta este mensaje como proveniente de una voz patriarcal -el padre o la sociedad en su conjunto- que critica la dedicación de Louise a su maternidad (Kaplan, 1998 [1983], 313). En la tercera panorámica el padre, Chris, está recogiendo sus 
cosas para abandonar el hogar y Louise le observa con la niña en brazos, desde la ventana.

Las panorámicas 4 a 9 muestran a Louise saliendo de casa para incorporarse al trabajo; observamos la preocupación con la que lo hace y su lucha por ser capaz de conciliar la vida laboral con el cuidado de su hija. Se hace amiga de Maxine, que le propone ir al sindicato para pedir que se pongan guarderías en el lugar de trabajo. De sus entrevistas con el sindicato observamos que la maternidad y las demandas de las mujeres trabajadoras son temas bastante ajenos a las preocupaciones del movimiento obrero, lo que excluye así de alguna manera a las mujeres como colectivo de la lucha de clases. Al término de la sección 9, Louise logra articular los interrogantes que de verdad la oprimen. Las panorámicas 10 a 12 replantean sentimientos y sensaciones ya tratadas, pero ahora desde la nueva seguridad que ha adquirido Louise. Primero, se reencuentra con su propia infancia a través de las fotos de un viejo álbum en la casa de su madre. Después se enfrenta a Chris de algún modo, mostrándose distante de él, mientras él intenta hacer que ella y Maxine se concentren en la película que quiere mostrarles y ellas hablan, distraídas, sobre sus cosas. La película que muestra Chris consiste en la lectura de un diario por parte de la artista feminista Mary Kelly y constituye una entrada a la interpretación psicoanalítica.

The theoretical voice, that of Mary Kelly, which supplies some elements of a metalanguage, is distanced from the mainstream of the diegesis in order to mark the movement to a different level of language. This speech could not be spoken by the sphinx because the sphinx uses not a metalanguage, but a counter-language. Access to a metalanguage, like access to memory, is, however, a condition of possibility for a counter-language, a necessary phase of Louise's journey through the word; and hence it is crucial that she (and the spectator of the film) should encounter this difficult theoretical text and, of course, that it should be spoken by a woman. (Wollen, 1981)

Esto culmina en la panorámica siguiente, cuando Louise interpreta un extraño sueño que Maxine ha tenido: "El lenguaje clínico [del texto leído] rompe el ritmo del lenguaje interior que Louise y las mujeres en general han utilizado para oponerse al lenguaje 'masculino' que predomina en la cultura. Pero inmediatamente queda compensada esa ruptura con la interpretación que hace Louise del sueño de
Maxine" (Kaplan, 1998 [1983], 316). En la última panorámica circular, Louise y Anna pasean por el Museo Británico observando las momias egipcias, y el lenguaje verbal, tanto los rótulos como la voz de la esfinge (la narradora) remite a lo que está pensando Anna. Su pensamiento la lleva a recordar unos acróbatas que ha dibujado.

The voice of the sphinx uses the first person pronoun with an unanchored reference, shifting between herself, Louise, and Louise's daughter (perhaps) in an ambiguous play of signification of the shifter. It is no longer possible to "fill" the symbolic place of the sphinx with a single fixed identification. There is a dispersal of the subject, dissociated from a single ego or consciousness. (Wollen, 1981)

La historia de Louise termina así y comienza el epílogo, que es paralelo al prólogo, con las mismas tres partes. Las acróbatas se retoman en la primera parte del epilogo, con imágenes luminosas y llenas de energía y en colores que "sugieren libertad, versatilidad y energía vital" (Kaplan, 1998 [1983], 318). Posteriormente, se repiten algunos de los planos de Laura Mulvey leyendo a cámara la explicación de las premisas del filme, esta vez con tomas nuevas en las que la vemos reflexiva, como planteándose y haciendo a las espectadoras plantearse de nuevo los presupuestos teóricos del filme. El cierre definitivo de la película son los planos de un juguete de laberinto, en el que hay que lograr que las bolitas de mercurio alcancen el centro. Esta última imagen remite a la idea de la búsqueda de una solución, una salida personal al tema de la expresión de la subjetividad de las mujeres.

\section{A MODO DE CONCLUSIÓN: CARACTERÍSTICAS DEL CINE EXPERIMENTAL DE MUJERES (1920-1979)}

La primera caracteristica destacable es el interés en mostrar la experiencia de las mujeres y en hacer deliberadamente películas desde su punto de vista como mujeres. Esto a veces se traduce en una reinterpretación o reelaboración de historias domésticas, como en el caso de Hands (Stella Simons), Jeanne Dielman (Akerman) o Riddles of the Sphinx (Mulvey y Wollen); también en el uso de materiales, por ejemplo la revalorización que Joyce Wieland hace de los tapices y telas como modo de expresión artística "femenino" relegado del concepto de arte al de "artesanía", 
- la máquina de coser de Annabel Nicolson en Reel Time (1973); y por supuesto, la expresión de la psique de las mujeres que persiguen Dulac y Deren o que destila de los diary films de Marie Menken ${ }^{12}$ y de los temas o ambientes de los que se ocupan típicamente los filmes "de mujeres" en la sociedad patriarcal; por ejemplo, el triángulo amoroso de Rainer en Lives of the Performers (1972) o los interiores opresivos de Akerman en Jeanne Dielmann (1975).

Un ejemplo diferente es L'Opera Mouffe (1958) de Varda, rodada cuando la cineasta estaba embarazada. Se abre con planos de una mujer embarazada desnuda a la que se opone, en el plano siguiente, una gran calabaza que es abierta a cuchillo y despojada de las semillas de su interior. El recorrido posterior por el barrio de La Mouffe y sus tipos humanos está entrecortado por planos que remiten de nuevo a la maternidad, con ciertas alusiones violentas, como, por ejemplo, una bombilla que es golpeada a martillo y cuando se abre (de forma similar a la cáscara de un huevo) se percibe en su interior la vida palpitante de un pollito que aún no ha terminado de formarse dentro de su "huevo" profanado.

Otra caracteristica significativa pone en contraste a los filmes experimentales de mujeres con los de las vanguardias masculinas y es una razón que a veces se esgrimió para excluirlas de los estudios críticos de estos movimientos. Se trata de la preocupación por el significado y la lealtad a éste, de modo que, al contrario que los filmes estructuralistas o materialistas y el "Expanded Cinema" muchas de mujeres cineastas experimentales procuran mantener vínculos con la narración. Esto llega a ser una posición política en el caso del cine que se autocalifica como "feminista": "women cannot be satisfied with an aesthetics that restricts counter-cinema to work on form alone. Feminism is bound to its politics; its experimentation cannot exclude work on content" (Mulvey, 1989 [1978], 124).

Otro aspecto recurrente en las directoras experimentales es su formación anterior y la vinculación de su labor cinematográfica con otras actividades artísticas 0 , como en el caso de Laura Mulvey, Dulac y Deren, criticas. Así, algunas de estas cineastas eran bailarinas (Deren, SteIla Simons, Sara Arledge, Shirley Clarke, Yvonne Rainer y Sally Potter, por ejemplo) y otras se dedicaban a las artes plásticas antes, durante y después de elaborar cortos de cine-arte (en Reino Unido Annabel Nicolson, y Yoko Ono,
Wieland, Schneemann, Storm de Hirsch, en EE.UU.). Entre las bailarinas destacan Yvonne Rainer en EE.UU. y Sally Potter en Inglaterra. Rainer es una de las pocas mujeres directoras norteamericanas que ha podido dirigir largos, manteniendo su personalidad creativa dentro de la difícil industria norteamericana. Potter, como Varda o Akerman, comenzó como directora de vanguardia, pero fue gestando un estilo peculiar que alcanzó grandes audiencias con su obra más importante, Orlando (1992), que le ha permitido mantener su propia productora cinematográfica y realizar filmes muy personales e innovadores.

Las mujeres cineastas experimentales también están muy preocupadas por la representación del cuerpo y la sexualidad femenina desde su punto de vista como mujeres. Es conocido el caso de Carolee Schneeman, que filmó Fuses (1967), en parte, como respuesta al filme de Brakhage Loving (1957) en el que la mostraba a ella y su pareja, James Tenney, manteniendo relaciones sexuales. Schneemann consideraba que Brakhage no había conseguido captar "[their] central eroticism" (Serra y Ramey en Blaetz ed., 2007, 109). A pesar del escándalo que causaban en la sociedad, este tipo de películas eran frecuentes en la Factoría Warhol, como también lo fueron las que recogían el cuerpo (femenino o masculino) de diferentes maneras. Por ejemplo, Yoko Ono en No 4 (Bottoms) (1966) y Fly (1970), en la que una mosca se pasea por el cuerpo desnudo de una mujer. Agnes Varda también produjo su propio manifiesto cinematográfico sobre el cuerpo: un corto titulado Réponse de femmes (1975) en el que un grupo de mujeres expresan verbalmente a cámara los fundamentos de la identidad femenina y un rechazo al uso del cuerpo en publicidad y como espectáculo erótico. El corto finaliza proponiendo que, junto con la "reinvención" de la mujer que promueve, ha de reinventarse también el amor. Por último, no podríamos cerrar este artículo sin mencionar la corriente dentro del cine experimental de mujeres que proviene de directoras lesbianas y que tiene algunas representantes ya en los 70, como la norteamericana Barbara Hammer (Multiple Orgasm, 1977; Double Strength, 1978).

La última caracteristica común a las cineastas de esta época que destacaremos es la búsqueda de lenguajes adecuados de expresión, aunque no desde concepciones esencialistas, sino utilizando o subvirtiendo los discursos existentes para generar nuevos mensajes. En la obra de 
directoras como Laura Mulvey y Jackie Raynal que hablan directamente a cámara, de Yvonne Rainer, que utiliza la danza, o Yoko Ono, que ofrece su versión desde el arte conceptual, hay una constante exploración del lenguaje para incluir su punto de vista personal como mujeres. Igualmente la hay en directoras como Potter, Varda o Akerman, que además de filmes experimentales también hicieron películas para públicos más amplios. Ann Kaplan destaca, por ejemplo, el uso del silencio y de la música para simbolizar un rechazo del lenguaje masculino en Nathalie Granger (1972) y se puede decir lo mismo de la asincronía entre imagen y sonido de India Song (1977), ambas de Marguerite Duras. Maggie Humm apunta a otras técnicas del lenguaje cinematográfico que a veces adoptan las cineastas feministas. La identificación con la cámara es una de ellas, con filmes que presentan fisuras en las que es posible percibir la presencia y la opinión de la autora. En otras ocasiones se trata de una ruptura de la ficcionalidad, a través de la cual el texto renuncia a la apariencia de realidad para dirigir preguntas a los espectadores, haciéndoles partícipes, moviéndoles a opinar y a implicarse en la interpretación del filme.
Terminaremos con unas palabras del cineasta de vanguardia y crítico británico Peter Gidal que resumen la relación que se establece entre el texto experimental y el espectador:

An Art film means that you spend ten hours putting together the artist's jigsaw puzzle and a non-art film means you get it right away. Either way you're being dominated, either way there's the artist with his ${ }^{13}$ jigsaw puzzle. I'm interested in the viewer not working out my meanings, but in doing a process, the way I'm doing a process, which may mean that the film I have and the film the viewer has are almost equal, but opposite. (Peter Gidal en John du Cane, 1972)

Las cineastas experimentales feministas nos mueven precisamente como espectadores a que hagamos ese esfuerzo interpretativo y participemos en el proceso de creación. Si bien este enfoque ha mantenido sus textos en los márgenes de la industria cinematográfica, también es cierto que ha desarrollado su capacidad expresiva y ha permitido una exploración nada desdeñable sobre el significado de la imagen de las mujeres y su participación en la creación de mensajes propios.

\section{NOTAS}

1 En el primero Ray propone un conjunto de texturas animadas, luces y objetos que danzan creando patrones visuales y Duchamp muestra espirales que giran constantemente provocando la ilusión de la visión tridimensional.

2 Horak hace una descripción bastante detallada sobre la sorprendente cantidad de cineastas no profesionales que realizaron trabajos experimentales en esa época, reunidos en cineclubs y más o menos cohesionados a través de la Amateur Cinema League (creada en 1926).

3 Sin embargo, Ann Kaplan afirma que no podemos considerar a Deren una feminista propiamente ya que "tuvo acceso a escasas ideas feministas [...] debido a la guerra y sus consecuencias, y por eso no desarrolló el feminismo consciente. No obstante, su propia carrera y el énfasis de sus películas en las psiques, los cuerpos, las situaciones de las mujeres, muestran su sensibilidad a lo que ahora denominamos cuestiones feministas" (Kaplan, 1983, 161).

4 Entre otros artículos de Dulac están: "L'Art des nuances spirituelles", en Cinéa-Ciné pour Tous, 1925; o "Les Esthètiques, les entraves, la cinégraphie intégrale", publicado en L'Art cinématographique, 1927.

5 Según recoge la analista Kathleen McHugh, las mujeres que practicaron la autobiografía cinematográfica estructuralista se ven excluidas en el estudio que el principal crítico del movimiento, P. Adams Sitney, dedica a este género. La razón es precisamente sus preocupaciones especificas, que incluyen premisas feministas: "Women's cinema and feminist film
Aceptado: 30 de mayo de 2011 
theory insist upon the significance of the personal and the extra-diegetic, but it is precisely that insistence that excludes them from this genre as defined by Sitney" (McHugh in Petrolle and Wright, 2005, 113).

6 Las técnicas experimentales se reducen a este énfasis en la duración temporal de las acciones, junto con un estilo "primitivo" de narración.

7 Solo están recogidos aquí algunos de los eventos más significativos para la corriente de teoría y crítica cinematográfica feminista durante los primeros años de la década de los 70, los que sucedieron en 1972. Estos años fueron muy productivos en actividades, publicaciones, asociaciones, congresos o cursos que por primera vez dedicaban atención específica al cine realizado por mujeres a ambos lados del Atlántico. Ruby Rich cita una breve cronología (Rich, 1998, 64-65).

8 Estas referencias raciales tienen otras connotaciones más complejas, que no podemos discutir en este breve artículo.

9 Si bien el texto había sido escrito en 1973 (Mulvey, 1989, 14).

10 No hay que olvidar que Mulvey sostenía en su artículo que cualquiera de las posiciones que adoptara la espectadora de los filmes clásicos era negativa para ella como sujeto individualizado. La crítica feminista posterior ha matizado mucho esta idea.

11 Wollen cita a cineastas como StraubHuillet, Jackie Raynal, Chantal Ackerman, Yvonne Rainer and Joyce Wieland, como referentes dentro de la vanguardia, afirmando a su vez que Mulvey y él buscaban "a confusion of identity between Europe and America" (Mulvey y Wollen en Johnston y Willemen, 1974, 6).

12 En EE.UU. Marie Menken está considerada como la creadora del subgé- nero experimental diary film, que se concentra en elementos sencillos de la vida cotidiana captados de manera espontánea y el uso de aspectos autobiográficos, como hace Chantal Akerman en News from Home (1977), en el que la lectura de las cartas de su madre se superpone a imágenes de la ciudad de Nueva York, donde vive. Es curioso que la húngara Martha Meszaros también utiliza el diario cinematográfico (aunque de diferentes características) y el cinéma verité que se observa en documentales sobre la vida de las mujeres durante los 60 y 70 en Reino Unido puede relacionarse con esta necesidad de utilizar la experiencia propia. El uso del propio cuerpo es frecuente también, como hacen Maya Deren, Yvonne Rainer, Yoko Ono y Sally Potter, por ejemplo.

13 El énfasis es nuestro.

\section{BIBLIOGRAFÍA}

Blaetz, Robin ed. (2007): Women's Experimental Cinema. Critical Frameworks, Durham \& London, Duke University Press.

du Cane, John (1972): "Extracts from a Talk with Peter Gidal", Time Out, Disponible en: http://www.luxonline.org.uk/ articles/peter_gidal(1).html. Consulta: 23/07/2011.

Chin, Daryl (2002): "Walking on Thin Ice: The Films of Yoko Ono", en Experimental Cinema. The Film Reader, eds. Wheeler Winston Dixon y Foster Gwendolyn Audrey, New York \& London, Routledge, 213-220.

Dixon, Wheeler Winston y Gwendolyn Audrey Foster eds. (2002): Experimental Cinema. The Film Reader, New York \& London, Routledge.
Heck-Rabi, Louise (1984): Women Filmmakers: A Critical Reception, Metuchen \& London, The Scarecrow Press. Holmlund, Chris (2007): "Excavating Visual Fields, Layering Auditory Frames: Signature, Translation, Resonance and Gunvor Nelson's Films", en Women's Experimental Cinema. Critical Frameworks, ed. Robin Blaetz, Durham \& London, Duke University Press, 67-88. Horak, Jan-Christopher (2002): "The First American Avant-Garde, 1919-1945", en Experimental Cinema. The Film Reader, eds. Wheeler Winston Dixon y Gwendolyn Audrey Foster, New York \& London, Routledge, 19-51.

Johnston, Claire y Willemen, Paul (1974): "Penthesilea, Queen of the Amazons, interview", Screen 15, 120-134. Disponible en: http://www.luxonline.org.uk/articles/Penthesilea_interview\%281\%29.html. Consulta: 24/07/2011.

Johnston, Claire (1973): "Women's Cinema as Counter Cinema" en Feminism and Film, ed. Ann Kaplan, Oxford, Oxford University Press, 2000, 22-33.

Kaplan, E. Ann (1983): Las mujeres y el cine: a ambos lados de la cámara, trad. M. ${ }^{a}$ Luisa Rodríguez Tapia, Madrid, Ediciones Cátedra, Colección Feminismos, 1998.

Kuhn, Annette (1994): Women's Pictures. Feminism and Cinema, 2. ${ }^{\text {a }}$ ed., London \& New York, Verso.

Landy, Marcia (1991): British Genres. Cinema and Society 1930-1960, Princeton, Princeton University Press.

Martin, Adrian (1999): "The Experimental Night: Jackie Raynal's Deux Fois". Disponible en: http://www.jackieraynal.com/files/2Fois-AdrianMartin.pdf. Consulta: 17/07/2011.

McHugh, Kathleen (2005): "History and Falsehood in Experimental Autobiography", en Women and Experimental Filmmaking, eds. Jean Petrolle y 
Virginia Wright Wexman, Urbana \& Chicago, University of Illinois Press, 107-128.

Millett, Kate (1970): Sexual Politics, Champaign, University of Illinois Press, 2000.

Miradas (redacción) (2011): "Germaine Dulac: femenino corazón de la vanguardia". Disponible en: http://www.eictv. co.cu/miradas/index2.php?option= com_content\&do_pdf $=1 \& i d=495$. Consulta: 22/07/2011.

Mounsef, Donia (2003): "Women Filmmakers and the Avant-Garde: From Dulac to Duras", en Women Filmmakers. Refocusing, eds. Jacqueline Levitin et al., London, Routledge, 3850.

Mulvey, Laura (1975): "Visual Pleasure and Narrative Cinema", en Visual and Other Pleasures, Bloomington \& Indiannapolis, Indiana University Press, 1989, 14-26.

Mulvey, Laura (1978): "Film, Feminism and the Avant-Garde", en Visual and Other Pleasures, Bloomington \& Indiannapolis, Indiana University Press, 1989, 111-126.

Petrolle, Jean y Wright Wexman, Virginia eds. (2005): Women and Experimental Filmmaking, Urbana \& Chicago, University of Illinois Press.

Rabinovitz, Lauren (2002): "The Woman Filmmaker in the New York Avantgarde", en Experimental Cinema. The Film Reader, eds. Wheeler Winston Dixon y Gwendolyn Audrey Foster, New York \& London, Routledge, 7180.

Rich, Ruby (1998): Chick Flicks. The Theories and Memories of the Feminist Film Movement, Durham \& London, Duke University Press.

Serra, M.M. y Kathryn Ramey (2007): “Eye/ Body: The Cinematic Paintings of Carolee
Shneemann", en Women's Experimental Cinema. Critical Frameworks, ed. Robin Blaetz, Durham \& London, Duke University Press, 103-126.

Sparrow, Felicity: "Annabel Nicolson". Disponible en: http://www.luxonline.org. uk/artists /annabel_nicolson/essay(2). html. Consulta: 20/07/2011.

Turim, Maureen (2005): "The Violence of Desire in Avant-garde Films", en Women and Experimental Filmmaking, eds. Jean Petrolle y Virginia Wright Wexman, Urbana \& Chicago, University of Illinois Press, 71-90.

White, Jerry (2005): "Chantal Akerman's Revisionistic Aesthetic", en Women and Experimental Filmmaking, Jean Petrolle y Virginia Wright Wexman, Urbana \& Chicago, University of IIIinois Press, 47-68.

Wollen, Peter (1981): "The Field of Language in Film", October 17. Disponible en: http://www.luxonline.org.uk/ articles/the_field_of_language_in_ film(1).html. Consulta: 25/07/2011.

\section{FILMOGRAFÍA}

Anemic cinema (Dir. Duchamp, 1926).

Christmas on Earth (Dir. Barbara Rubin, 1963).

Chronik der Ana Magdalena Bach (Dir. Straub-Huillet, 1968).

Cleo de 5 á 7 (Dir. Agnes Varda, 1961).

Cut Piece (Dir. Yoko Ono, 1960-70).

Dance in the Sun (Dir. Shirley Clarke, 1953). Deux fois (Dir. Jackie Raynal, 1971).

Double Strength (Dir. Barbara Hammer, 1978).

Erection (Dir. Yoko Ono, 1971).

Fly (Dir. Yoko Ono, 1970).

Fuses (Dir. Carolee Schneemann, 1967). Hands (Dir. Stella Simon, 1928).
India Song (Dir. Marguerite Duras, 1977). Introspection (Dir. Sarah K. Arledge, 1946). Je, tu, il, elle (Dir. Chantal Akerman, 1974). Jeanne Dielman, quai de Commerce 1080, Bruxelles (Dir. Chantal Akerman, 1975).

L'opera Mouffe (Dir. Agnes Varda, 1958).

L'une chante, I'autre pas (Dir. Agnes Varda, 1977).

La coquille et le clergyman (Dir. Germaine Dulac, 1927).

La pointe courte (Dir. Agnes Varda, 1955). La retour á la raison (Dir. Man Ray, 1923). La souriante Mme Beudet (Dir. Germaine Dulac, 1922).

Lives of the Performers (Dir. Yvonne Rainer, 1972).

Loving (Dir. Stan Brakhage, 1957).

Meshes of the Afternoon (Dir. Maya Deren y A. Hammid, 1943).

Multiple Orgasm (Dir. Barbara Hammer, 1977). Nathalie Granger (Dir. Marguerite Duras, 1972).

News from Home (Dir. Chantal Akerman, 1976).

No 4 (Bottoms) (Dir. Yoko Ono, 1966). No 5 (Smile) (Dir. Yoko Ono, 1968).

Orlando (Dir. Sally Potter, 1992).

Penthesilea, Queen of the Amazons (Dir. Laura Mulvey y Peter Wollen, 1974). Rape (Dir. Yoko Ono, 1969).

Reel Time (Dir. Annabel Nicolson, 1973).

Réponse de femmes (Dir. Agnes Varda, 1975). Rhythm in Light (Dir. M. Ellen Bute, 1935).

Riddles of the Sphinx (Dir. Laura Mulvey y Peter Wollen, 1977).

Song of the Shirt (Dir. Sue Clayton y Jonathan Curling, 1979).

Syncromy n. 2 (Dir. M. Ellen Bute, 1936). Three Lives (Dir. Kate Millet, 1971).

Thriller (Dir. Sally Potter, 197?).

Up your Legs for Ever (Dir. Yoko Ono, 1970).

VW Vitesses Women (Dir. Claudine Eizykman, 1974). 